\title{
LOGÍSTICA APLICADA NO PROCESSO DE PRODUÇÃO DE OVOS COMERCIAIS
}

\author{
Logistics Applied in Commercial Egg Producer Process
}

Daiana Fatima Detofol ${ }^{1}$ Jamir Rauta ${ }^{2}$

César Augustus Winck ${ }^{3}$

Recebido em: 09 ago. 2017

Aceito em: 08 mar. 2018

Resumo: O presente estudo refere-se à logística aplicada em uma empresa Avícola, produtora de ovos comerciais, e tem por objetivo principal propor melhorias no processo logístico de armazenamento e transporte de ovos in natura. A logística é área estratégica nas organizações, sendo indiferente o ramo de atuação desta, responsabilizando-se por processos de armazenamento, estocagem, movimentação e transporte. A cadeia de suprimentos visa garantir operações seguras e integradas à gestão estratégica e planejada, de modo a gerar redução de custos, tempo e desperdícios, buscando o aumento da rentabilidade. Empregou-se no estudo, a metodologia exploratória, em forma de estudo de caso por meio de observação, aplicação de questionário semiestruturado, e consequente estratificação e análise das informações obtidas. Conclui-se que em todo o processo de movimentação da empresa estudada, há a possibilidade de promover mudanças, desde que, ocorra a utilização de técnicas corretas de logística, alvejando assim, a obtenção de progresso no processo, como: redução do tempo destinado às atividades e da mão de obra, e melhoria da satisfação dos colaboradores. Os resultados obtidos reforçam a necessidade de melhorar a gestão dos recursos no processo produtivo, para que se consiga a obtenção de produto final com a qualidade desejada pelo mercado.

Palavras-Chave: Estratégia. Competitividade. Agronegócios. Avicultura.

Abstract: The present study refers to the logistics applied in a poultry company, commercial egg producer, and its main objective is to propose improvements in the logistic process of storage and transportation of eggs in natura. Logistics is a strategic area in organizations, being indifferent its branch of activity, being responsible for processes of storage, storage, movement and transportation. The supply chain aims to guarantee safe and integrated operations to the strategic and planned management, in order to generate reduction of costs, time and waste, seeking the increase of profitability. The exploratory methodology was used in the study, in the form of a case study through observation, application of a semi-structured questionnaire, and consequent stratification and analysis of the information obtained. It is concluded that in all the process of movement of the studied company, it is possible to promote changes,

\footnotetext{
1 Bacharel em Engenharia de Produção; UNISEP - FEFB; daianadetofol@hotmail.com.

2 Doutorando em Agronegócios (UFRGS); jamirrauta27@gmail.com.

3 Doutor em Agronegócios (UFRGS); UNOESC; cesar.winck@unoesc.edu.br.
} 
provided that, the use of correct logistics techniques occurs, thus targeting the achievement of progress in the process, such as: activities and the workforce, and improving employee satisfaction. The results obtained reinforce the need to improve the management of resources in the production process, so that the final product can be obtained with the quality desired by the market.

Keywords: Strategy. Competitiveness. Agribusiness. Poultry farming.

\section{INTRODUÇÃO}

A logística é uma área funcional das empresas, sendo considerada estratégica, pois trata de questões relacionadas ao transporte, movimentação, estoque e armazenamento de produtos, gerando grande volume dentro dos custos operacionais, condicionado à integração das cadeias de suprimentos, onde é necessário atender aos níveis de serviço, manter o padrão de qualidade, baixos custos e visando a competitividade.

$\mathrm{Na}$ indústria alimentícia, o valor agregado dos produtos exerce influência nos consumidores no momento da compra. No Brasil, o consumo de ovos comerciais gira em torno de 140 unidades per capita por ano (AVISITE, 2013; ASGAV, 2015), chegando a uma produção aproximada de 37 bilhões de unidades em 2014 (ABPA, 2015). Logo, estudar e implantar logística na cadeia produtiva dos ovos in natura torna-se uma necessidade, pela fragilidade do produto e custos empregados para sua produção.

Nos últimos anos, o setor tem se adequado para atender às exigências do consumidor, implantando programas que elevam o padrão de qualidade dos produtos, visando à preservação do meio ambiente, promovendo sustentabilidade.

A obtenção de ovos comerciais in natura tem origem na criação de galinhas, seguindo normas rígidas de controle durante as operações produtivas e, ao fim do processo, entregar ao consumidor um produto dentro das exigências legais, sanitárias, e segurança alimentar. Mediante ao dito, entende-se que a logística é a visão empresarial mais adequada para coordenar o processo, obtendo os resultados planeados.

A logística como área de atuação e conhecimento humano existe há muitos anos. $A$ literatura tradicional chama a atenção para a origem militar, e sua importância aparece desde a antiguidade (PIRES, 2007).

Neste contexto, encadeando logística com a produção de ovos comerciais, enquadram-se todos os processos, com abrangência de escopo desde a armazenagem dos ovos na granja (sala de ovos) até a recepção na planta processadora (entreposto), cuja definição está relacionada a compreender as peculiaridades e similares de cada etapa. Para consolidar o estudo de caso, centro deste estudo, será apresentada, de forma simplificada, a aplicação e importância da logística no armazenamento e transporte de ovos in natura.

O trabalho se divide em objetivo geral, que visa propor melhorias no processo logístico 
de armazenamento e transporte de ovos in natura. Para tanto, e como objetivo especifico, identificar fatores que provocam perdas durante o processo de transporte e armazenagem dos ovos em uma empresa Avícola, situada na Região Sudoeste do Estado do Paraná. Para tanto, se fez vital conhecer todo o processo logístico da empresa, identificando os pontos críticos, com a ideia de aperfeiçoar o tempo de chegada de ovos no setor de entreposto (classificação de ovos).

O estudo se justifica pelo uso corrente do produto Ovo pela população em geral, pela necessidade de profissionalização da logística na empresa estudada, dificuldades encontradas nos trajetos, como estradas e rodovias mal conservadas, e o não entendimento estratégico da logística para as organizações. O conhecimento para o processo logístico contribui para evitar falhas e desperdícios, possibilitando alavancar vendas ao dispor de maior estoque, com menores ou inexistentes avarias, perdas e custos extras.

O problema proposto para este trabalho baseou-se na identificação das principais causas que afetam o processo logístico decorrente de muitas perdas no manuseio, armazenagem e transporte de ovos in natura comerciais. Isto porque os problemas geralmente afetam os lucros da empresa, principalmente pela demora em perceber as causas e encontrar soluções viáveis.

Apesar da tecnologia disponível em termos de transporte para as organizações, verifica-se que ainda existem gargalos a serem solucionados, como rodovias e estradas secundárias danificadas, demora na carga e descarga dos produtos e falta de acessibilidade. Além de rotas erradas, gastos excessivos com combustíveis, lubrificantes e manutenções de veículos, horas extras de colaboradores e a falta de gerenciamento na cadeia de suprimentos. $\mathrm{Na}$ atualidade, considera-se que a logística de estoque e transporte alcançam valores aproximados de 50 a $70 \%$ do custo logístico total.

A qualidade dos produtos e o diferencial garantem clientes (BALLOU, 2011). Diante do exposto, o problema abordado por este estudo foi: De que forma a logística pode influenciar no resultado da rotina de transporte e armazenagem de ovos comerciais in natura?

O estudo se concentrou entre o processo de recebimento do produto na sala de ovos da granja, até a recepção no entreposto/ processadora. Para tanto, empregou-se metodologia exploratória, em forma de estudo de caso, aplicado nas instalações da empresa Avícola, localizada no município de Francisco Beltrão, na região sudoeste do estado do Paraná. O período da pesquisa in loco ocorreu de agosto até outubro de 2015. sendo aplicada observação in loco, para avaliar e estudar os vários métodos disponíveis, identificando limitações, ou não, a respeito de implicações e utilizações, através de questionário semiestruturado.

Sendo assim, o objetivo geral do presente estudo foi propor melhorias no processo logístico de transporte e armazenamento de ovos comerciais das granjas até a empresa avícola estudada. 


\section{REFERENCIAL BIBLIOGRÁFICO}

O termo "logística" e sua aplicação data da década de 1940, a partir de atividades militares. Apresentando uma evolução constante, adquiriu uma presença estratégica dentro das organizações, de maneira integrada e em comunhão com a Supply Chain Management SCM, tendo por finalidade melhorar o desempenho em longo prazo das empresas como um todo (LEITE, 2003), englobando funções dentro e fora da empresa, garantindo valor para os clientes (PIRES, 2007).

A competitividade e implantação da melhoria contínua, fomentaram a aplicação de logística como gestão de materiais, armazenamento, transporte e entrega de produtos (matéria prima e acabados) em tempo hábil, local certo, maneira correta, a um custo justo.

Logística pode ser definida como a parte do processo da cadeia de suprimentos que planeja, implementa e controla o eficiente e efetivo fluxo e estocagem de bens, serviços e informações relacionadas, do ponto de origem ao ponto de consumo, visando atender aos requisitos dos consumidores (MOURA, 2004; FILHO, 2007; NOVAES, 2007). Complementando, para Rodrigues (2002), o conceito de logística pode ser entendido como adquirir, manusear, transportar, distribuir e controlar eficazmente os bens disponíveis.

De modo a apresentar uma cadeia de suprimentos na prática, pelo viés da logística, optou-se por já apresentar a cadeia de produção dos ovos comerciais, assunto deste trabalho. Pode-se observar na Figura 1 o processo que inicia na granja e termina no consumidor final.

Figura 1 - Cadeia de suprimentos de ovos comerciais in natura.

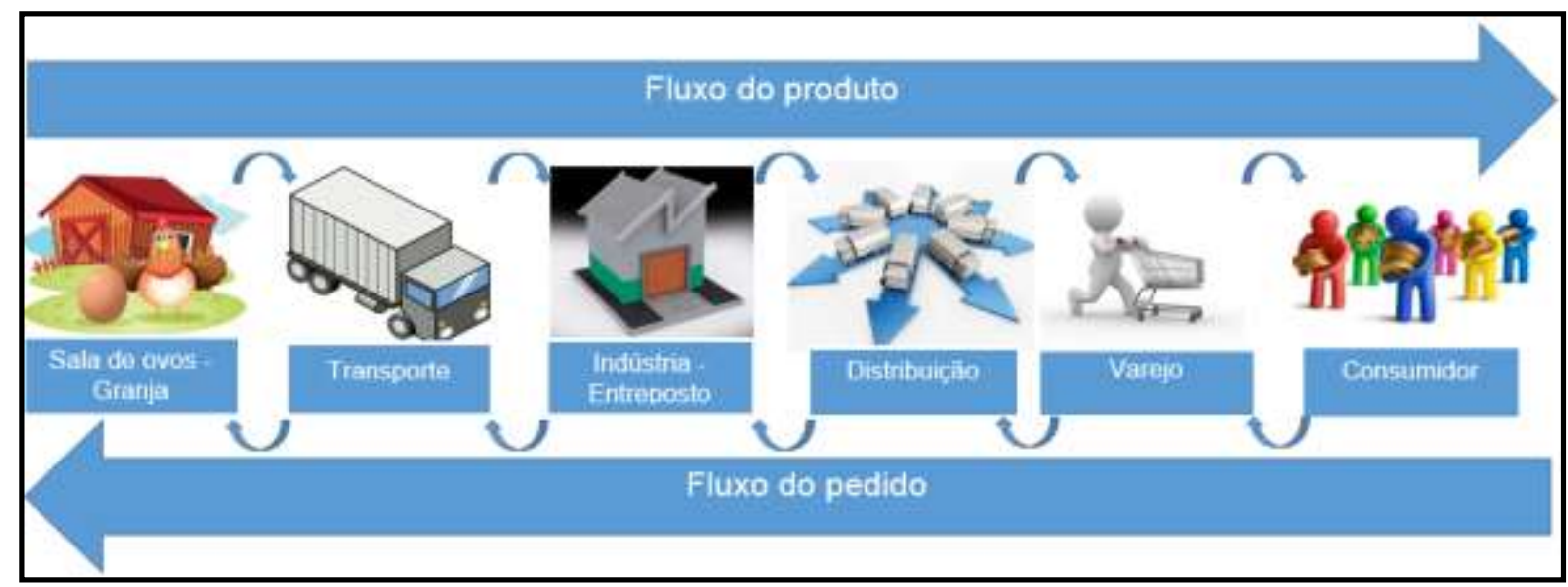

Fonte: Os autores, 2018.

Um sistema de transporte pode ser compreendido como todas as atividades, os recursos e as demais facilidades (armazéns, depósitos e recursos de movimentação) que se relacionam à capacidade de movimentar bens numa determinada economia. Isso significa movimentar pessoas, produtos e serviços (FILHO, 2007; CHING, 2008; FLEURY, 2009).

Armazenagem pode ser definida como sendo o conjunto de atividades para manter 
fisicamente estoques de forma adequada. Demanda que sejam solucionadas questões referentes à localização, ao dimensionamento da área, ao arranjo físico, à alocação dos estoques, aos projetos de docas e configuração dos armazéns, à tecnologia de movimentação interna, à estocagem e aos sistemas (BERTAGLIA, 2003; FARIA, 2003; GUARNIERI, 2006).

\section{O MERCADO DE OVOS NO BRASIL}

No Brasil a cadeia produtiva de ovos caracteriza-se pela produção de ovos in natura e industrializados. A produção predominante é feita no sistema de criação em aviários nas granjas, composta por produtores independentes de pequeno e médio porte (DONATO, 2009). Em 2011, cerca de 0,89\% da produção brasileira de ovos foi destinada ao mercado externo, sendo $11,46 \%$ a fração de ovos processados. Fração que tende a aumentar devido à facilidade de comercialização e armazenamento de ovos (MAIA, 2013).

O sistema agroindustrial de ovos, movimenta R\$ 1.1 bilhão por ano no Brasil, sendo $23 \%$ destinado a rações, $12 \%$ aos salários e $25 \%$ à distribuição. Entretanto, possui pontos fracos, como: a relação informal entre produtores e compradores; lenta modernização; baixo crescimento; pouco investimento em pesquisas e a falta de conhecimento dos produtores.

Os principais estados brasileiros de ovos são Minas Gerais, Paraná, Rio grande do Sul, Pernambuco e São Paulo. O último é o maior produtor de ovos, com alojamento de 2,61 milhões de aves de postura, que representa 35,55\% do total do Brasil (SARTÓRIO, 2012).

\section{METODOLOGIA}

A pesquisa construiu-se de maneira exploratória descritiva (MALHOTRA, 2001), via estudo de caso (YIN, 2001), pesquisa de campo e observação, onde foram acompanhadas as etapas do processo de produção de ovos, iniciando pela chegada do produto in natura na sala de ovos, seu armazenamento, empilhamento, carregamento e principalmente o transporte: entre sala de ovos (granja) até o entreposto ou processador.

A escolha da empresa deu se por conveniência, proximidade e contato do pesquisador com os responsáveis da empresa.

Foram realizadas entrevistas e aplicados questionários semiestruturados aos agentes envolvidos no processo, sendo o diretor administrativo da empresa, o responsável pelo transporte, o supervisor de produção (recebimento dos ovos na empresa), três motoristas e cinco produtores de ovos (granja). Os questionários fitavam a identificação de falhas (pontos fracos) e possíveis geradores destes problemas, caracterização do processo, da empresa e das granjas, e sugestões de melhorias.

A finalidade foi a obtenção de informações, caracterizando o grau de frequência de determinado fenômeno, sua natureza, características, causas, relações e conexões com outros 
fenômenos (DENCKER, 2004). Em complemento, usou-se pesquisa bibliográfica e documental (BARROS e LEHFELD, 2007; PRODANOV E FREITAS, 2013).

\section{RESULTADOS E DISCUSSÕES}

A empresa foco deste estudo, será chamada apenas de Avícola, iniciou suas atividades em dezembro de 1971 no Município de Francisco Beltrão, Estado do Paraná, onde está instalada atualmente. Possui 150 colaboradores diretos, e mantém uma produção média/semana de 910.000 ovos in natura.

Em seu portfólio encontram-se, a linha de postura: ovos orgânicos, ovos caipiras e ovos vermelhos convencionais. Comercializados para grandes redes de supermercados, como Pão de Açúcar e Wal-Mart. Por fim, a linha de corte: ovos férteis e pintainhos de um dia. Onde $100 \%$ da produção é direcionada para uma empresa parceira que industrializa e exporta a carne de frango.

Naturalmente, a empresa possui o sistema de inspeção federal - SIF, habilitação para exportação, e possui seus processos monitorados pelo Ministério da Agricultura e Pecuária MAPA. Igualmente, os ovos proveem de granjas inspecionadas e enquadradas no Programa Nacional de Sanidade Avícola - PNSA, e as matérias primas são produzidas de acordo com o GlobalGap (Sistema Integrado de Garantia da Produção) e as IT (Instruções de Trabalho).

As aves de postura são da linhagem Shaver Brown, recriadas em aviários de piso, e na fase de produção são mantidas em gaiolas, respeitando densidade e outros requisitos de bemestar animal, com acompanhamento veterinário próprio da empresa. Onde os ovos são coletados ao menos três vezes ao dia e pré-classificados de forma manual. Depois, são acondicionados em bandejas, armazenados em ambiente adequado, permanecendo neste local por no máximo 48 horas até a expedição.

O processo de armazenamento dos ovos comerciais, é caracterizado por uma sala de portas que evitam a entrada de moscas, insetos e pragas (camundongos, baratas, aranhas e etc.), possuem forros e devem permitir o armazenamento dos produtos afastados do chão e paredes, além de arejadas com temperatura ambiente, onde os ovos ficam dispostos em bandejas de polpa.

O fluxograma da Figura 2, apresenta o caminho percorrido pelos ovos in natura, com destaque na transição entre a sala de ovos e entreposto. 
Figura 2 - Fluxograma do processo.

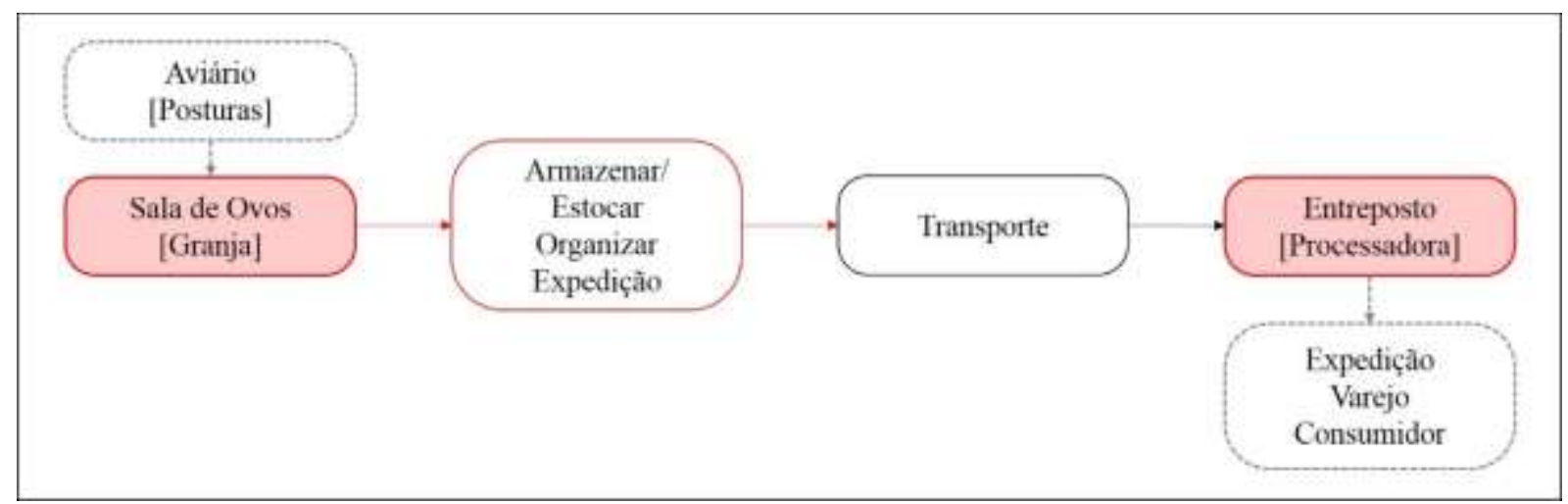

Fonte: Dados da pesquisa, 2018.

A expedição da granja para o entreposto é realizada seis vezes por semana, e os ovos devem estar preparados com a identificação de lote, data de produção e o tipo de ovo. Sendo que para ovos orgânicos a etiqueta de identificação é na cor azul, ovos convencionais na cor verde, e caipira na cor branca. Antes do envio para a expedição, deve-se analisar se os produtos estão segregados e identificados, e a altura para a expedição não deve ultrapassar 15 bandejas.

No registro de processo, as especificações da ficha de registro individual de cada produtor devem condizer com as informações recolhidas pelo motorista, contendo, quantidades de bandejas previstas e carregadas, data de produção, tipo de ovos e produtor. Somente após a conferência, o produto estará apto ao carregamento. O local para essa atividade deve ser de fácil acesso, com dimensões condizentes para o meio de transporte (caminhão baú) realizar o carregamento.

$\mathrm{Na}$ expedição, o carregamento é manual, onde o motorista e o produtor levam 10 (dez) bandejas por vez (Imagem 1), (fotos 1 e 2), condicionando-as em paletes (já acondicionados) dentro do baú do caminhão (foto 4), obedecendo à altura de 15 (quinze) bandejas. Entre os paletes, é colocada uma chapa de compensado fina e um papelão que fazem a separação, evitando o contato entre produto e possível quebra. 
Imagem 1 - Carregamento manual de ovos - processo.

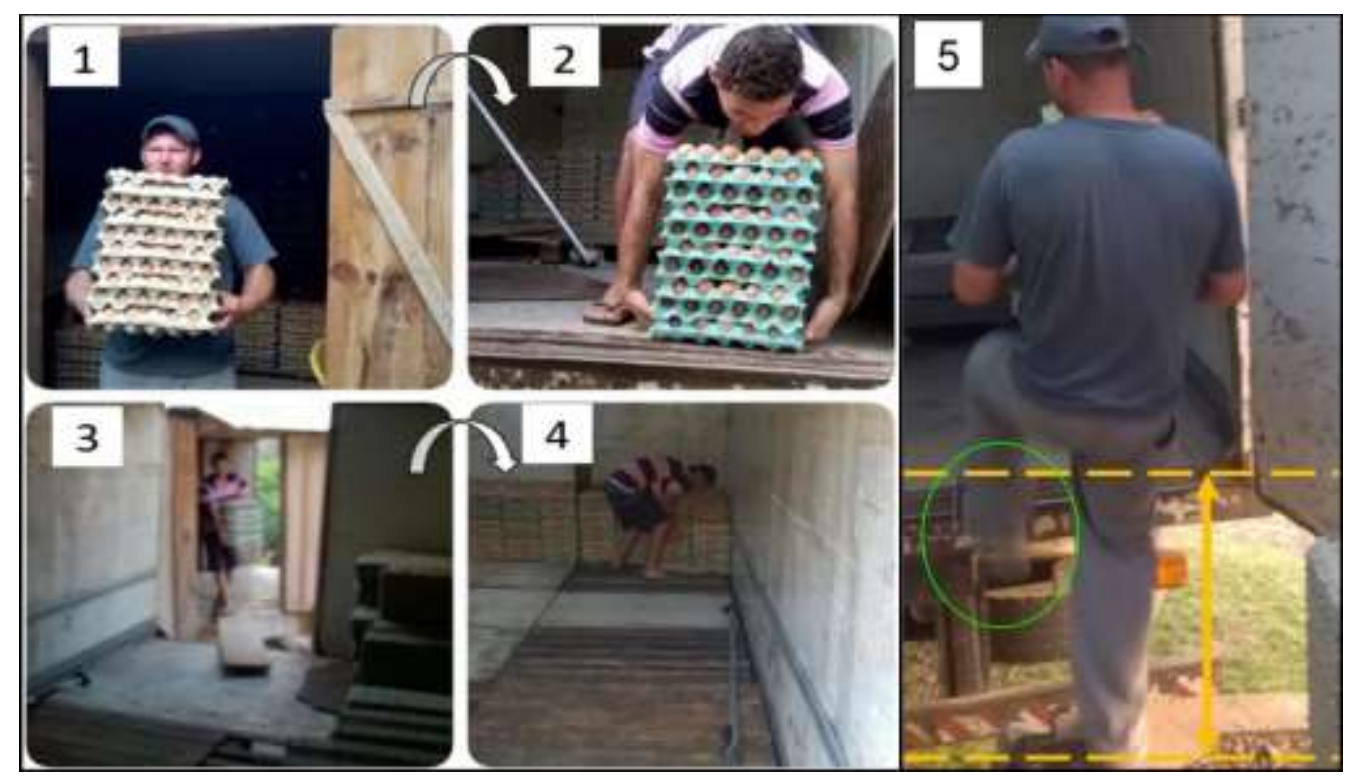

Fonte: Dados da Pesquisa, 2018.

Na Imagem 2, observa-se que a movimentação do produto é realizada sobre uma "tábua de madeira" (Foto 3), prejudicando a visibilidade e podendo gerar desiquilíbrio do profissional, ocasionando assim, acidentes de trabalho, uma vez que há um desnível entre o veículo e a sala de armazenamento. Outra falha é notada na foto 5 , onde o carregador igualmente não tem visão total, e apoia o pé na beira da carroceria, não the condicionado segurança. Tais situações observadas nessa operação, demanda maior tempo entre o início e fim da atividade, podendo ir de 45 a 60 minutos, conforme os entrevistados expuseram.

O levantamento realizado mostrou que, na movimentação manual, o peso das dez bandejas é de aproximadamente $18 \mathrm{~kg}$, estando dentro do recomendado que é de $60 \mathrm{~kg}$ (CLT, 2015).

Mediante ao constatado, melhorias se fazem necessárias, aja vista que o produtor e motorista estão expostos a problemas pela postura incorreta, monotonias, movimentos repetitivos, riscos de possíveis quedas e outros acidentes causados por improvisos ou descuidos. Para Assunção (2006), trabalho repetitivo implica mobilização do aparelho locomotor, sendo definido em termos de força e duração na unidade de tempo. Em relação à execução de ciclos de trabalho, onde há duração inferior a 30 segundos, ocorrendo mais de uma vez durante a realização de uma tarefa, considera-se trabalho repetitivo.

Adentrando nas sugestões de melhorias, optou-se por fazer um teste piloto, criando dois ciclos de carregamento. Sendo o tradicional (manual), e o segundo utilizando-se uma paleteira manual. Para efetivação do teste, descreveu-se as atividades, que foram cronometradas durante a atividade. Os resultados podem ser constatados na Tabela 1. 
Tabela 1 - Descrição operacional: Tempo. "Ciclo de trabalho"

\begin{tabular}{|c|c|c|}
\hline \multirow{2}{*}{ Descrição atividade - Carregamento manual de ovos } & \multicolumn{2}{|c|}{ Tempo } \\
\hline & Real & Prescrito \\
\hline 01 - Pegar bandejas sala de ovos; & $02^{\prime \prime}$ & - \\
\hline 02 - Levar bandejas no caminhão; & $10^{\prime \prime}$ & - \\
\hline 03 - Colocar sobre o palete; & $04^{\prime \prime}$ & - \\
\hline 04 - Retornar na sala de ovos; & $08^{\prime \prime}$ & - \\
\hline 05 - Fazer a limpeza do local de trabalho se necessário; & - & $06^{\prime}$ \\
\hline 06 - Locomoção para outra granja 20 a 60 minutos, obtendo média de & & $40^{\prime}$ \\
\hline Tempo total do ciclo transporte manual de ovos & $24^{\prime \prime}$ & $46^{\prime}$ \\
\hline
\end{tabular}

\begin{tabular}{l|l|l}
\hline Descrição atividade - Carregamento paletizado de ovos & & \\
\hline 01 - Pegar palete com ovos; & $10^{\prime \prime}$ & \\
\hline 02 - Levar no caminhão; & $16^{\prime \prime}$ & \\
\hline 03 - Colocar no local adequado; & $08^{\prime \prime}$ & \\
\hline $04-$ Retornar na sala de ovos; & $12^{\prime \prime}$ & \\
\hline 05 - Fazer a limpeza do local de trabalho se necessário; & - & $06^{\prime}$ \\
\hline 06 - Locomoção para outra granja 20 a 60 minutos, obtendo média de: & & $40^{\prime}$ \\
\hline Tempo total do ciclo transporte paletizado de ovos & $46^{\prime \prime}$ & $46^{\prime}$ \\
\hline
\end{tabular}

Fonte: Dados da Pesquisa, 2018.

No carregamento manual de ovos, o tempo real do ciclo de trabalho analisado foi de 24 segundos. Sendo assim, a atividade relatada é repetitiva. Já no carregamento paletizado, observa-se que o ciclo de trabalho foi de 46 segundos. Desta forma, não se caracteriza como repetitividade. Já, o tempo prescrito em ambos é de 46 minutos, e o colaborador desempenha as atividades fora do ciclo real.

Para uma melhor compreensão, a Figura 3 apresenta a relação entre os dois ciclos, onde a diferença básica, está no sistema paletizado, que realiza apenas uma viagem, evitando trabalho monótono, e evita os riscos constatados, assim como, na eliminação de possíveis ameaças a saúde e bem-estar dos carregadores e na perda dos ovos por tombamento. 
Figura 3 - Framework de comparação entre os ciclos de carregamento - teste piloto.

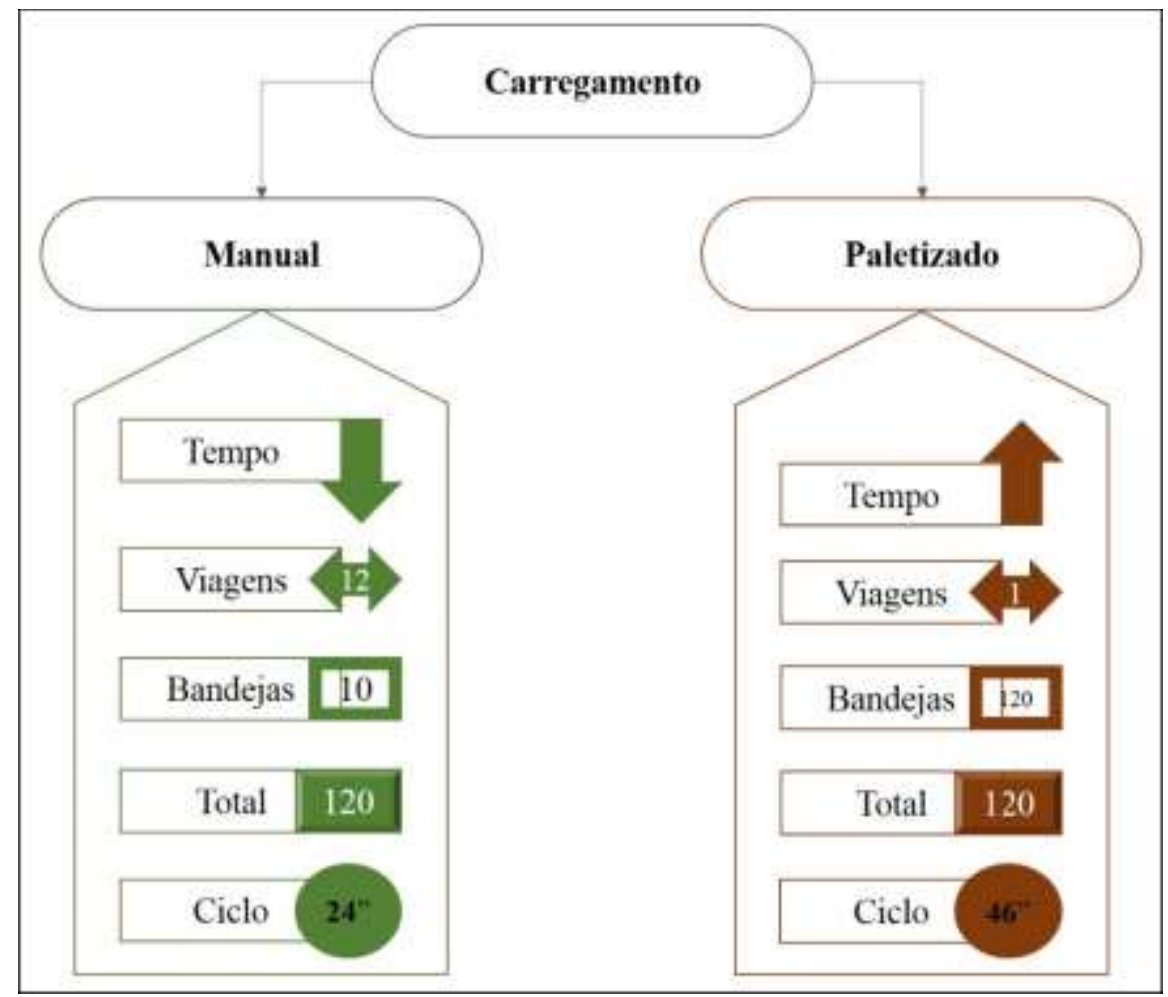

Fonte: Dados da pesquisa, 2018.

Para a empresa, o procedimento manual gera custos, pois o tempo para transportar as bandejas e a ordenação no caminhão causam lentidão no carregamento, atrasando a coleta em outras propriedades e provocando horas extras, aumentando os custos de produção.

Entendendo a importância da segurança, tanto para o funcionário, quanto para os produtos, de modo também que se diminua custos, sugeriu-se a implantação e uso do sistema de paletização na granja - sala de ovos. A ideia é usar uma paleteira manual para levar os paletes prontos - com as bandejas de ovos - da sala até o interior do caminhão.

Devido à logística de movimentação e às evoluções do transporte, a infraestrutura de transporte, no aspecto carregamento, é um fator fundamental para a redução de custos (BERTAGLIA, 2003).

Diante do proposto e dando continuidade ao projeto piloto, a empresa, juntamente com dois produtores parceiros, adaptou 2 (duas) salas de ovos para o novo modelo de carregamento. Os produtores foram treinados em relação ao acondicionamento dos ovos nas bandejas, essas nos paletes, e sobre o manuseio da paleteira.

Dos ajustes mais relevantes e necessários para o novo processo, uma das granjas ampliou a porta de acesso à sala de ovos, para a entrada e a saída da paleteira com os produtos. Na outra, foi elevado o terreno por meio de terraplanagem, a fim de nivelar a altura do furgão do caminhão com a sala de expedição. 
Após a implantação do projeto piloto, identificou-se a necessidade dos produtores de permanecerem com paletes e bandejas de polpas extras, com o intuito de agilizar o processo de montagem de novos lotes, deixando a próxima carga já pronta e formalizada.

As ações supracitadas proporcionaram a diminuição em 2 (duas) horas por semana, reduzindo horas extras e tornando o processo mais eficiente. A mão de obra requerida inicialmente era de três pessoas (produtor, motorista e ajudante), passando a ser de duas pessoas (motorista e ajudante), liberando o produtor para exercer outras atividades.

A gestão de estoque da empresa e as atividades de logística resumem-se ao produto. A movimentação no novo sistema implica que seja realizado o reaproveitamento de espaços. o layout da sala de ovos foi alterado, adequando-o a um tamanho suficiente para o manuseio da paleteira. Com o novo sistema de paletização, o transporte das bandejas tornou-se mais rápido e fácil. A Imagem 2 mostra as adaptações realizadas na sala de ovos e a disposição no caminhão.

Imagem 2 - Sala de ovos adaptada para sistema paletizado.
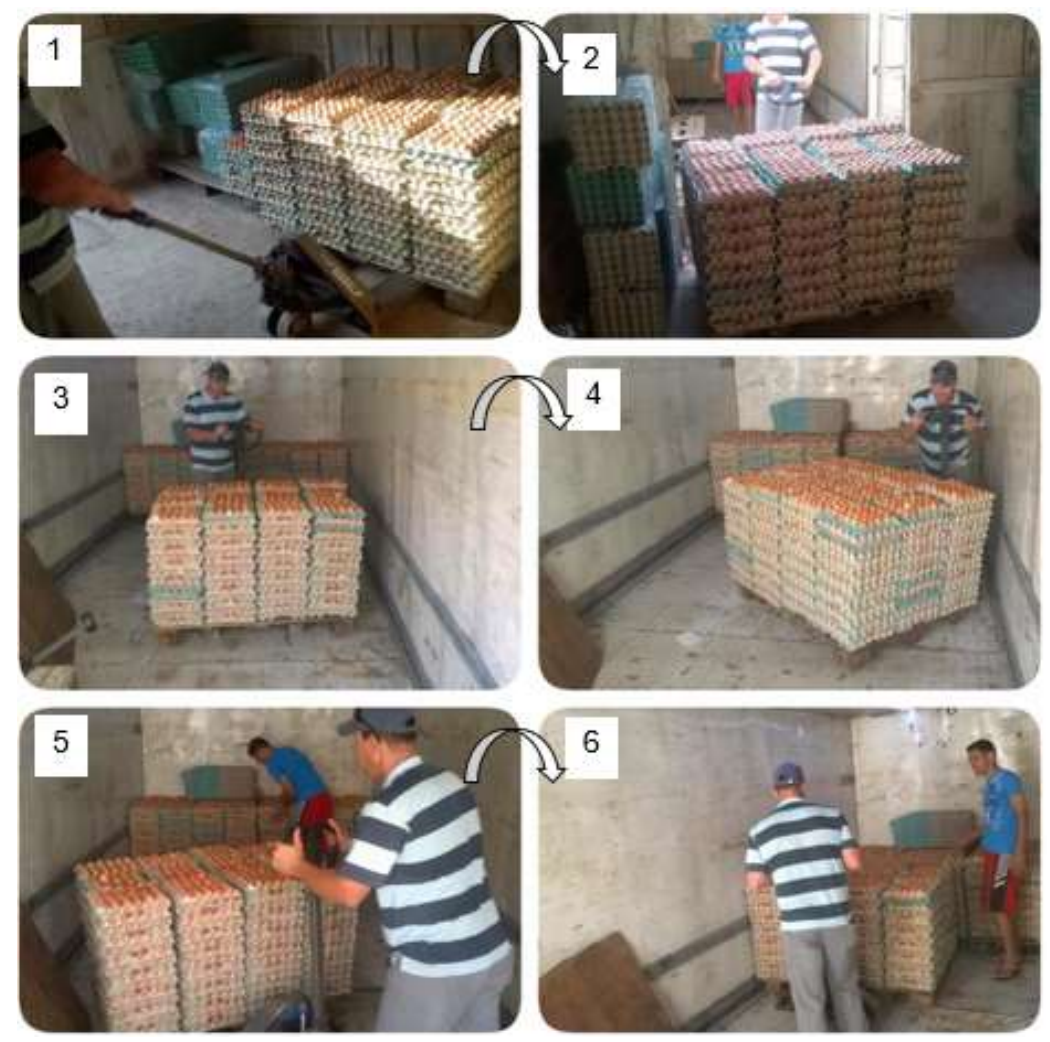

Fonte: Dados da pesquisa, 2018.

Com a alteração do layout, os principais ganhos foram: agilidade na disposição de estocagem dos produtos e no carregamento, e ambiente com melhor aspecto e maior espaço. Os envolvidos no processo demonstraram sentimento de bem-estar em razão da facilidade de manuseio e da economia de tempo que obtiveram na função exercida.

Considerando aspectos presentes no desempenho de atividades e rotina de trabalho, 
optou-se por analisar e mensurar ganhos de produtividade. As Tabelas 2 e 3 descrevem o comparativo de tempo entre os produtores 01 e 02, que foram analisados neste estudo.

Tabela 2 - Comparativo de tempo produtor 01.

\begin{tabular}{|c|c|c|c|c|c|}
\hline \multirow{5}{*}{$\begin{array}{l}\text { Produtor } \\
\underline{01}\end{array}$} & \multicolumn{2}{|c|}{ Sistemas | Tempo/ minuto } & Quantidade de Ovos & \multirow{2}{*}{\multicolumn{2}{|c|}{$\begin{array}{l}\text { Diferença de Tempo } \\
\text { Manual para paletizado }\end{array}$}} \\
\hline & Manual & Paletizado & Coletas & & \\
\hline & 45 & 29 & \multirow{3}{*}{$\begin{array}{l}\text { Unidades granja } \\
10.800 \\
360 \text { bandejas/3 palete) }\end{array}$} & 16 & \multirow{3}{*}{ Minutos $\downarrow$} \\
\hline & 46 & 30 & & 16 & \\
\hline & 48 & 30 & & 18 & \\
\hline
\end{tabular}

Fonte: Dados da Pesquisa, 2018.

Para medir a eficiência do novo processo, foram analisadas suas características antes e depois da implantação, além do tempo para desempenhar as atividades. A média para o sistema manual foi de 46 minutos para o produtor 1 (Tabela 3) e 48 minutos para o produtor 2 (Tabela 4), logo a média geral é 47 minutos.

Tabela 3 - Comparativo de tempo produtor 02.

\begin{tabular}{|c|c|c|c|c|c|}
\hline \multirow{5}{*}{ Produtor $\underline{02}$} & \multicolumn{2}{|c|}{ Sistemas | Tempo/ minuto } & Quantidade de Ovos & \multicolumn{2}{|c|}{ Diferença de Tempo } \\
\hline & Manual & Paletizado & Coletas & \multicolumn{2}{|c|}{ Manual para paletizado } \\
\hline & 50 & 29 & \multirow{3}{*}{$\begin{array}{l}\text { Unidades granja } \\
10.800 \\
360 \text { bandejas/3 palete) }\end{array}$} & 21 & \multirow{3}{*}{ Minutos $\downarrow$} \\
\hline & 47 & 31 & & 16 & \\
\hline & 48 & 30 & & 18 & \\
\hline
\end{tabular}

Fonte: Dados da Pesquisa, 2015.

Com a implantação do sistema paletizado, o tempo gasto diminuiu. Enquanto o produtor 1 obteve um ganho de tempo de 16 minutos, no produtor 2, foi de 18 minutos. E o trajeto entre sala de ovos e caminhão, se reduziu para uma única vez com o sistema de paletização, conforme Imagem 3. 
Imagem 3 - Sistema manual e paletizado.

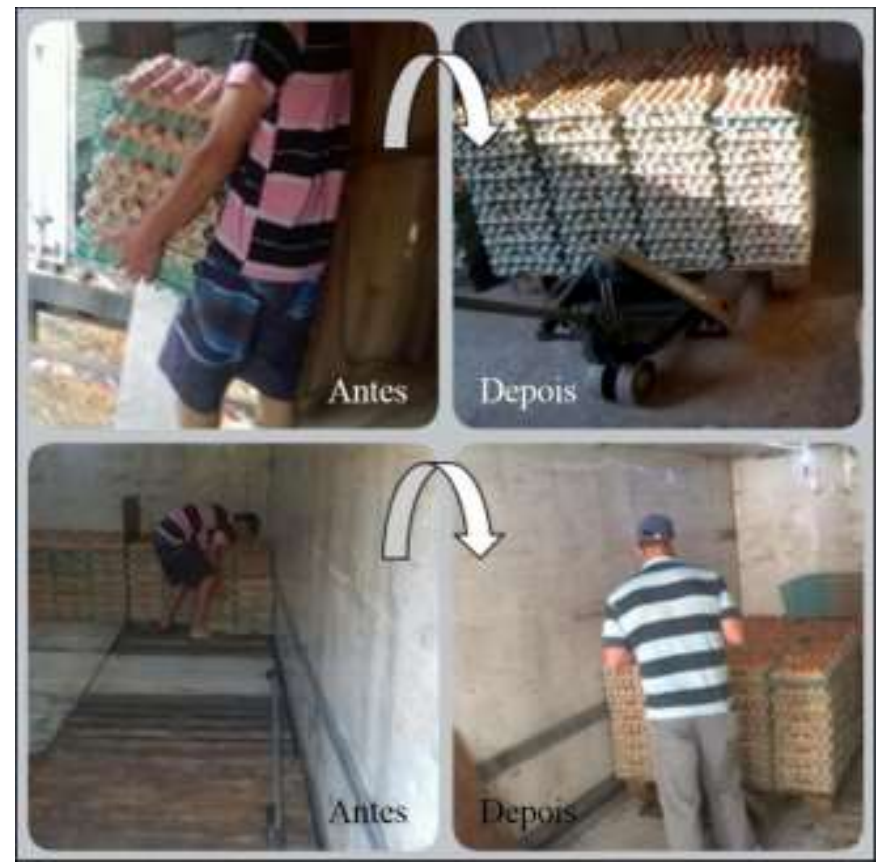

Fonte: Dados da Pesquisa, 2018.

De acordo com produtores e colaboradores, benefícios foram alcançados com as mudanças, como agilidade no carregamento, redução do esforço físico e repetitividade de movimentos, além de organização da sala de ovos e diminuição do número de acidentes. Ressaltaram ainda, que, antes da implementação do sistema de paletização, o motorista trabalhava até 12 (doze) horas em determinados dias da semana. Atualmente, conforme levantamento realizado trabalha-se no máximo 10 horas.

O motorista da empresa, juntamente com o ajudante, faz o transporte e a acomodação dos produtos dentro do caminhão, respeitando as normas de proteção da carga. Em seguida, o caminhão é deslocado para outra propriedade, onde repetirá o mesmo procedimento. Tal atividade foi reduzida para uma única vez

Vale ressaltar que é um projeto-piloto. Logo, nem todas as propriedades estão adequadas ao novo sistema estrutural. Nas demais granjas, o trabalho ainda é realizado de forma manual.

Por meio do estudo, a empresa definiu que todas as granjas já cadastradas devem se adequar ao novo sistema e as que iniciaram uma nova parceria já devem dispor de estrutura condizente com o projeto indicado.

Com a análise final do projeto piloto, foi possível discernir a redução de tempo entre os sistemas manual e paletizado, de $44 \%$ no carregamento do produtor 01 e $58 \%$ no produtor 02. Portanto, conclui-se que o projeto implantado se mostrou eficaz no processo de carregamento de ovos in natura. 
Para uma empresa cuja produção são ovos comerciais in natura, a logística desempenha função importante no transporte dos produtos, pois o modal rodoviário representa $65 \%$ de todo o volume transportado, conforme pesquisa realizada por Menchik (2004). Observou-se na empresa estudada, que o deslocamento percorrido entre a granja (sala de ovos) e o entreposto ocorre pela via rodoviária, sendo agravado pelas precárias condições das estradas.

A definição da rota comercial tem papel importante na cadeia de suprimentos, pois consiste em apresentar um sistema de informação que possibilita planejamento de melhor trajeto e veículo. Com a roteirização, busca-se o menor custo e maior eficácia.

Este estudo analisou as duas rotas previamente definidas para os produtores 01 e 02 , que implantaram o projeto-piloto de paletização. Concluiu-se que as rotas utilizadas estão corretas, pois são de fácil acesso, com menor distância, atendendo os pré-requisitos de menor tempo, melhor rota, e menor custo de transporte.

A distância percorrida para a coleta de ovos in natura, entre o produtor 01 e o entreposto é de $42 \mathrm{~km}$, com tempo médio de 45 minutos. Já, entre o produtor 02 e o entreposto são $58 \mathrm{Km}$, com o tempo de percurso de $1 \mathrm{~h} 15 \mathrm{~min}$.

O problema do trajeto está nas estradas rurais, onde há má conservação, excesso de buracos, declives, provocando trepidação, fatores estes que podem danificar o produto. 0 trajeto realizado em asfalto causa menos impactos, mas, como a pavimentação contém má formação, ocorrem problemas de vibração.

O nível de vibração sofrido pelos produtos durante o transporte depende do tamanho do lote, da qualidade da embalagem, velocidade empregada pelo condutor, aceleração, número de frenagens, tipo de suspensão do veículo e calibragem dos pneus, bem como, distância percorrida.

A roteirização, quando aplicada de forma correta, beneficia o sistema com maior agilidade. Gera redução de custos, aumenta a eficiência e a competitividade da empresa no mercado.

No entreposto, durante a recepção dos ovos, é conferida a etiqueta de identificação do lote e data de produção. A quantidade expedida e a classificação por tipo são verificadas nas fichas de registro. As perdas de ovos decorrentes do transporte representam para a empresa prejuízo. Aproximadamente 3,5\% desses danos ocorrem desde a coleta na granja até a expedição do produto para o cliente final, considerando ainda que passará por outras etapas de manuseio, nas etapas de descarga, armazenamento e exposição na gôndola de supermercado.

Para o transporte, é utilizado caminhão próprio do tipo baú, cargo, não climatizado, com paredes e assoalho impermeabilizados, dimensões de $7 \mathrm{~m}$ de comprimento, 2,44 $\mathrm{m}$ de largura, 2,15 m altura, com 02 eixos. A capacidade de carregamento do caminhão é de 
aproximadamente 14 paletes, sendo 180 bandejas cada, com 30 ovos, totalizando 75.600 ovos por puxe. Cada ovo com gramatura média de 60 gramas, bandejas com dimensões de $30 \mathrm{~cm}$ x30cm, empilhadas, as quais são distribuídas na carroceria do veículo.

Outro fator de perda observado são os danos aos elementos internos (albúmen, gema e membrana), além de quebras na casca, devido à agitação do produto durante o transporte. As condições visuais destes ovos quanto à presença de sujidades, trincas, quebras e deformações são avaliadas no ato do recebimento.

No entreposto ocorre a retirada dos paletes do caminhão com auxílio da paleteira manual. Nessa etapa, é realizada a conferência da quantidade de ovos recebidos, confrontando com a quantidade descrita em ficha de registro recebida junto com a carga. Em seguida, esses paletes seguem para a sala de recepção, onde também se conferem as etiquetas.

Após a recepção, os ovos seguem para a máquina classificadora, passando pela lavagem e secagem. Em seguida, para o setor de ovoscopia ${ }^{4}$. Na sequência, são pesados e encaminhados para os boxes, embalados automaticamente na embalagem primária e manualmente na secundária. Finalizando o processo, seguem para a estocagem e expedição, onde serão encaminhados ao cliente final.

Com o estudo realizado e as análises feitas, verifica-se que de nada adianta esforços na produção, se todos os setores da cadeia de suprimentos não funcionam perfeitamente.

Contudo, conclui-se que uma logística bem planejada, estudada e aplicada de forma correta garantem um excelente armazenamento, estocagem e transporte de ovos in natura até o ponto de distribuição, como também se diminui a emissão de fumaça, e outros impactos gerados pelo transporte, contribuindo com o meio ambiente.

\section{CONSIDERAÇÕES FINAIS}

Com este estudo, buscou-se inicialmente aprimorar os conhecimentos sobre a aplicação da logística na produção de ovos comerciais, mostrando a importância e impacto que as técnicas de gerenciamento logístico podem ofertar às empresas que as utilizar.

A Avícola estudada possui um processo pouco estruturado, logisticamente falando. Mesmo possuindo preocupação com a qualidade de seus produtos, fato este evidenciado pelos métodos de controles internos, além de cuidados com o meio ambiente e a satisfação dos seus clientes.

Ao aplicar este estudo, a logística na empresa Avícola passou a ter uma função administrativa, e por se dizer, estratégica, na qual foi realizada a gestão do valor do tempo, bem como o lugar dos produtos a serem armazenados e distribuídos através do meio de

\footnotetext{
${ }^{4}$ Setor onde se identificam e retiram os ovos com avarias.
} 
transporte. Tentou-se conciliar o fluxo de informações dos processos, para a movimentação dos materiais e produtos em direção aos clientes.

O modal escolhido para o transporte de ovos in natura é o rodoviário, devido ao sistema de carregamento na sala de ovos na propriedade produtora, à fragilidade do produto, às condições de armazenamento e ao transporte do lote da granja até o entreposto (classificação do produto, processamento e saída).

Após observações e analises, identificaram-se falhas, principalmente na transição da sala de ovos até o interior do caminhão (baú), armazenamento e transporte. Mediante as constatações, a empresa permitiu intervenções, no sentido de reestruturação do processo, por estar em situação de vulnerabilidade, podendo afetar diretamente o rendimento na atividade dos produtores, motoristas, demais colaboradores, e até mesmo da empresa como um todo.

No processo de carregamento de ovos in natura ocorriam falhas ocasionando perdas do produto, tempo ocioso, fadiga nos colaboradores e consequente custo para a empresa. Então se procurou propor melhorias com ações de baixo custo e melhor performance, proporcionando rentabilidade.

Assim, sugeriu-se um projeto-piloto para as atividades de carregamento e transporte de mercadorias, iniciando em duas granjas parceiras. Para tanto, necessitou-se que ambas se adequassem aos novos padrões, como organização da sala de ovos e nivelamento do terreno.

Em comum acordo, produtores e gestores da Avícola optaram por implantar um equipamento simples ao processo, chamado "paleteira manual", a qual minimizaria esforço físico, reduziria tempo de coleta e mão de obra no processo.

Após a implantação deste projeto piloto, observou-se que o resultado foi positivo, pois todos os objetivos propostos inicialmente foram alcançados, satisfazendo as expectativas de todos os envolvidos no processo, inclusive diminuindo em média 16 minutos o tempo de carregamento, refletindo na diminuição de horas extras na empresa, diminuindo assim custos operacionais.

Através do estudo de caso, constataram-se benefícios oriundos da aplicação de logística, com destaque, a implantação de um padrão de armazenamento, estocagem, carregamento e transporte, enfatizando a inserção do sistema paletizado, sendo simples e produtivo. Vale ressaltar o ganho de tempo, a saúde dos funcionários (motoristas e ajudantes) com a redução do esforço físico, e principalmente a satisfação dos produtores e colaboradores envolvidos no processo.

Portanto, a logística quando bem aplicada, reduz custos e eleva a satisfação, aumentando o nível de serviços e a qualidade do produto final. De natureza condizente, entende-se que o objetivo geral preconcebido, foi atingido. Onde se submeteu melhorias no processo, originando ganhos de tempo e diminuição de custos para empresa Avícola. Recomenda-se para estudos futuros, a implementação do sistema de paletes baseado na 
estrutura proposta neste trabalho, a qual pode ser expandida para todos os parceiros (produtores). Como também, realizar um estudo de análise da viabilidade econômica e rentabilidade com a implantação em toda a cadeia produtiva.

\section{REFERÊNCIAS}

ABPA, Associação Brasileira de Proteína animal. Disponível em: <www.abpa-br.com.br>. Acesso em: 05.09.2015.

ASGAV, Associação Gaúcha de Avicultura. Disponível em: <http://www.asgav.com.br>. Acesso em: 04.11.2015.

ASSUNÇÃO, A. A. Lesões por esforços repetitivos: Determinantes, Fatores de risco e Aspectos Ergonômicos. Belo Horizonte: Notas de aula do III Curso de Especialização em Ergonomia da Universidade Federal de Minas Gerais, set. 2006b.

AVISITE, A cadeia Avícola analisada do ovo ao consumidor. Disponível em:

<http://www.avisite.com.br/revista/pdfs/revista_edicao32.pdf>. Acesso em: 01.10.2015

BALLOU, R.H.; Logística empresarial: Transportes, administração de materiais e distribuição física. São Paulo: Atlas, 2011.

BARROS, A.J.S.; LEHFELD, N.A.S.; Fundamentos de metodologia científica. 3.ed. São Paulo: Person, 2007.

BERTAGLIA, P. R.; Logística e gerenciamento da cadeia de abastecimento. 1.ed. São Paulo: Saraiva, 2003.

CHING, H.Y.; Gestão de estoques na cadeia de logística integrada. 3.ed. São Paulo: Atlas, 2008.

DENCKER, A. F. M.; Métodos e técnicas de pesquisa em turismo. São Paulo: Futura, 2004.

DONATO, D. C. Z.; GRANDA, E. R. S.; GARCIA, P. D.; REIS, C. B.; GAMEIRO, A. H. A questão da qualidade no sistema agroindustrial do ovo. In: 470 Congresso da Sociedade Brasileira de Economia, Administração e Sociologia Rural. Porto Alegre: Anais do SOBER, 2009.

FARIA, A. C.; Logístico, Custos. Uma abordagem na adequação das informações de Controladoria à gestão da Logística Empresarial. São Paulo, Tese de Doutorado, USP, 2003.

FILHO, E. R. Transporte e modais: com suporte de TI e SI. Curitiba: Ibpex, 2007.

FLEURY, P.F., WANKE, P.; FIGUEIREDO, K.F.; Logística empresarial. 1. ed. São Paulo: Atlas, 2009.

GUARNIERI, P.; Nível de Formalização na Logística de Suprimentos da Indústria Automotiva. Análise do Caso das Montadoras. Dissertação (Mestrado em Engenharia de Produção) Universidade Tecnológica Federal do Paraná. Ponta Grossa, 2006. 
LEITE, P. R.; Logística reversa: meio ambiente e competitividade. São Paulo: Prentice Hall, 2003.

MAIA, R. C.; TAVERNARI, F. C.; ALBINO, L. F. T.; LELIS, G. R.; Tecnologias de processamento de ovos. Revista: Avicultura Industrial, no 02, ano 104, Ed 1219, 2013.

MALHOTRA, N. K.; Pesquisa de Marketing - Uma Orientação Aplicada. 3o ed. Porto Alegre: Bookman, 2001.

MENCHIK, C. R. A.; Nova fase da logística no Brasil. Publicado em 24/11/2004. Disponível em: $<w w w$.ibralog.org.brz. Acesso em 01.11.2015.

MOURA A. R.; Dicionário de Logística. São Paulo: IMAN, 2004.

NOVAES, A. G.; Logística e gerenciamento da cadeia de distribuição. Rio de Janeiro: Eusevier, 2007.

PIRES, S. R. I.; Gestão da cadeia de suprimentos: Conceitos, estratégias, práticas e casos. 1.ed. São Paulo: Atlas, 2007

PRODANOV, C. C.; FREITAS, E. C.; Metodologia do trabalho científico: Métodos e técnicas da pesquisa do trabalho acadêmico. 2a Ed, Novo Hamburgo, Universidade Feevale, 2013.

RODRIGUES, P. R. A.; Introdução aos sistemas de transporte no Brasil e à logística internacional. São Paulo: Aduaneiras, 2002.

SARTÓRIO, L. A.; Baixa Oferta. Revista Avicultura industrial. Ano no 06, ano 103, Ed 1212, 2012.

YIN, Robert K.; Estudo de Caso: Planejamento e Métodos. Trad. Daniel Grassi, 2o ed. Porto Alegre: Bookmann, 2001. 